\title{
Paradigma PReVentivo e lógica identitária nas ABORDAGENS SOBRE O HIP HOP ${ }^{\star}$
}

\author{
Rodrigo Lages e Silva $\star \star$ \\ Rosane Neves da Silva ${ }^{\star \star \star}$
}

\begin{abstract}
Resumo
Este artigo faz uma revisão das pesquisas acadêmicas sobre o Hip Hop, apontando a preponderância do conceito de identidade nas referidas teorizações. Neste sentido, pretende-se contextualizar a ascensão do conceito de identidade nas visões sobre o Hip Hop, em direção a sua conjugação com o conceito de cidadania. Tal lógica identitária está intimamente ligada à construção da noção de categorias desviantes. Forjada sob o pano de fundo da urbanização, a lógica identitária é a expressão acadêmica de uma racionalidade a que denominamos de paradigma preventivo, cuja função é antecipar-se a uma eventual potência violenta que os jovens moradores de periferia representariam. Portanto, tratase de entender a fabricação do subúrbio e da juventude como problema social, analisando, assim, as concepções que dão sustentação aos ideais corretivos e moralizantes que as abordagens sobre o Hip Hop expressam através de uma ênfase nos seus beneficios identitários.
\end{abstract}

Palavras-chave: Hip Hop. Identidade. Insegurança. Psicologia Social.

\section{Preventive Paradigm and identitary logical in the VIEWS OF HIP HoP}

\begin{abstract}
This article makes a revision of the academic researches about Hip Hop, indicating the emphasis on identity concept in those related theories. We aim to contextualize the growth of identity in the views of Hip Hop, pointing to its combination with citizenship concept. Such identitary logical is narrowly connected with the construction of the desviating categories notion. Forged on the backstage of urbanization, the identirary logical is the academic expression of a rationality which we named preventive paradigm, that intents to anticipate

$\star$ Apoio: CAPES

$\star \star$ Mestre PPGPSI UFRGS. Endereço: Faculdade Dom Alberto. Rua Ramiro Barcelos, 892 Centro. CEP: 90010-310 - Porto Alegre, RS - Brasil E-mail: lagesesilva@gmail.com

$\star \star \star$ Professora PPGPSI UFRGS. Endereço: Universidade Federal do Rio Grande do Sul, Instituto de Psicologia, Departamento de Psicologia Social e Institucional. Rua Ramiro Barcelos, 2600 - sala 13 - Santana. CEP: 90035-003 - Porto Alegre, RS - Brasil E-mail:rosane.neves@ufrgs.br
\end{abstract}


an eventual violent potential of youth living in outskirts. Therefore, this article is about understanding the production of outskirts and youth like a social problem, thus analyzing the conceptions which support the corrective and moral ideals that are expressed in the Hip Hop researches through their emphasis on its identitary benefits.

Key-words: Hip Hop. Identity. Insecurity. Social Psychology.

\section{INTRODUÇÃO}

Após os movimentos contraculturais dos anos 1960 e 1970 o mundo experienciou um período de aparente calmaria no cenário cultural. Porém, enquanto o mainstream observava o envelhecimento e a acomodação da geração que inovou com propostas estéticas e comportamentais vanguardistas, no guetto americano, jovens criaram à sombra da grande mídia um importante movimento cultural que ganhou expressividade a partir dos anos 1980.

A tradução aproximada que se pode obter da expressão Hip Hop é "salto com os quadris". Hip significa, segundo o Dicionário Oxford, quadril, e Hop, pequeno salto ou pulo. A conjugação dessas duas palavras para designar o conjunto de expressões artísticas compreendendo o rap, o grafite e o break, somente apareceu quando, em 1981, África Bambaataa nomeou Hip Hop a manifestação cultural surgida no Bronx, bairro de predominância negra em Nova Iorque, no início dos anos $1970^{1}$. Através de uma expressão gráfica transgressora constituída pelo grafite, de um estilo musical inovador quanto à proposta rítmica e melódica como o rap, e de um modo de dançar igualmente original, cujos movimentos interpretam a descontinuidade e a velocidade dos beats repetitivos produzidos pelo disque jóquei que é o break, o Hip Hop abrange diversas manifestações artísticas que se popularizaram como "arte de rua". Os primeiros protagonistas deste movimento foram, na sua maioria, jovens, negros ou descendentes hispânicos, moradores dos bairros periféricos de Nova Iorque. Atualmente, seus adeptos encontram-se espalhados por diversos países e etnias, não deixando, contudo, de seguir exprimindo um forte teor de contestação racial, especialmente, no que se refere à afirmação dos negros diante da hegemonia branca.

O movimento Hip Hop apareceu fortemente na mídia a partir dos anos 1980 e se mundializou ao final desta mesma década, quando também começou a ganhar força no Brasil. Em São Paulo, nos encontros informais de jovens na Rua São Bento, próximo à estação do metrô, os primeiros hiphoppers brasileiros dançavam break ao som do que ainda era muito mais conhecido sob o signo geral de música black do que como Hip Hop. Atualmente, embora ainda seja uma expressão cultural enraizada nas periferias, o Hip Hop é também um produto de consumo como outro qualquer. Nos Estados Unidos da América é um dos gêneros musicais que gera maior lucratividade para a indústria fonográfica. Seu impacto como produto cultural é notado na maior parte dos países, através 
de sua especial habilidade para se misturar não apenas com outras formas musicais globais, como o rock, techno e reagge, mas também com as regionais, tais como o funk carioca e o kuduro. ${ }^{2}$

Embora não constitua uma regra geral, diversos raps abordam temas de "conscientização" das periferias ao falar sobre o cotidiano de discriminação e de falta de oportunidades a que estão sujeitos a maioria dos jovens nascidos nos subúrbios ou nas favelas. Estendendo-se da temática da pertença étnica para a da pobreza, por vezes até mesmo com letras de conteúdo polêmico, de apologia às drogas ou à violência (gangstarap), o Hip Hop passou a constituir um ponto de convergência para diversos modos de inconformidade: tanto para a juventude marginalizada, quanto, eventualmente, para jovens mais favorecidos que buscavam, através do Hip Hop, expressar sua insatisfação com os modos hegemônicos de subjetivação.

É neste contexto ambíguo, de uma midiatização intensa e de um vigor junto aos jovens das periferias urbanas, que passamos a nos interessar por possíveis estratégias de resistência engendradas a partir do Hip Hop. Pesquisamos inicialmente a bibliografia acadêmica e jornalística disponível sobre o assunto. Surpreendeu-nos, contudo, a constatação de que o Hip Hop vem se integrando ao senso-comum e, consequentemente, ao discurso acadêmico, por meio de uma potência corretiva e adaptativa. Parece haver um consenso nas abordagens educacionais, sociológicas e psicológicas ao enfatizarem os aspectos "corretivos" ou "preventivos" que o Hip Hop desempenharia nas periferias $^{3}$ dos centros urbanos.

Nosso objetivo neste artigo será o de problematizar essa concepção naturalizada do Hip Hop, demonstrando que essa perspectiva é produzida de acordo com uma lógica que busca ancoragem no conceito de "identidade". Assim, explicitaremos os motivos pelos quais as abordagens sobre a temática Hip Hop parecem convergir em torno de uma "lógica identitária" e as estratégias pelas quais esta lógica se articula com uma potência corretiva, moralizante, cuja sustentação é um sentimento generalizado de insegurança que está, por sua vez, imbricado com determinada atitude antecipatória a que vamos chamar de "paradigma preventivo".

\section{HiP HoP E LÓGICA IDENTITÁRIA}

No pensamento psicológico, a questão da identidade tem ocupado um lugar de destaque. A ênfase identitária é mais evidente nas abordagens ditas terapêuticas, mas está presente até mesmo nas abordagens ditas "sociais", levando-se em consideração certas abordagens que tomam o indivíduo como unidade primeira do social. O ideal de sujeito que responde por este modelo é o da estabilidade, da individualidade. O social nesta lógica identitária é apenas um local no qual se pode construir, através do mecanismo da identificação, uma identidade "boa", "normal", "estável"; ou "desviante", "anormal", "patológica", "de risco". 
Inicialmente, encontramos estas concepções na bibliografia voltada para o Hip Hop a partir do entendimento de que o mesmo funcionaria como "espaço de identificação". Trata-se, aparentemente, da tomada da identificação como algo construtivo, que atua no sentido do reforço das potencialidades do sujeito. Nesta abordagem, o Hip Hop constituiria um facilitador para que se operasse uma "identificação positiva" dos jovens negros e moradores da periferia.

Observamos tal perspectiva em Scandiucci (2005, p. 20) que, na sua abordagem jungiana, vê o Hip Hop para o jovem como uma "possibilidade de assumir uma identidade mais próxima de sua realidade". Fica evidente, no entanto, o entendimento da identidade como um princípio que opera na perspectiva da estabilidade, da normalidade, da adequação à sua realidade. Uma concepção que compreende a realidade de uma forma descontínua em relação à subjetividade. A identidade operando, por conseguinte, como um mecanismo de aproximação entre um mundo "interior", subjetivo, e uma realidade social, cultural. Não se compreende a produção da realidade e a produção da subjetividade como um mesmo processo. Perspectiva análoga é expressa em Matsunaga (2004, p. 70, grifo nosso):

Ao nos depararmos com os movimentos juvenis, e em nosso caso o movimento hip hop, compreendemos que esses grupos conseguem fornecer aos jovens espaços para a identificação quanto ao lugar que moram, ao lugar que ocupam no tecido social, à sua condição juvenil, às suas particularidades culturais entre outros aspectos. Possibilitam aos jovens que dele fazem parte, construir uma identidade coletiva.

Podemos perceber, nesta afirmação, um entendimento de identidade coletiva que não deixa de estar mediado pelo ideal do indivíduo adaptado ao social. Trata-se do coletivo em favor do individual e, conseqüentemente, de um sujeito sempre dependente de "espaços para a identificação". Essa perspectiva pressupõe o "coletivo" como a mera soma das individualidades.

Ensaiando uma ampliação deste tipo de referencial, sem, entretanto abandonar a perspectiva identitária, Rosana Martins (2005, p. 144) apontou, também sobre o Hip Hop, que:

[...] ao resgatar uma dimensão social da subjetividade, propomos simplesmente evitar modelar o indivíduo com base em um único sujeito determinante, mas em diferentes circunstâncias do espaço híbrido, dando margem ao aparecimento de um eu plural inquieto.

Em seguida, ela retorna ao tema da identidade, agora como uma identidade plural, multifacetada. "Afinal, as identidades não são fixas, mas se articulam com a estrutura das relações sociais através das identificações como de raça, gênero, classe, etnicidade, nível educacional, gostos, etc.” (MARTINS, 2005, p. 144).

Mesmo partindo de uma perspectiva mais ampla que inclui dimensões como raça, gênero, classe, etc., a autora parece apontar para uma determinada funcionalidade 
da noção de identidade, no sentido de "resgatar uma dimensão social", como se houvesse um distanciamento entre o social e o individual. Neste contexto, o Hip Hop atuaria como um elemento facilitador, na função de mediar a aproximação dessas duas dimensões.

Abramovay et al. (2002, p. 138), em pesquisa financiada pela Unesco sobre os modos de organização juvenis, afirmam que os rappers realizam um "esforço de construção de identidade coletiva mediante a crítica social". A crítica social deixa de ser um elemento de transformação para constituir-se como instrumento de afirmação da identidade. Esvazia-se todo o sentido do que pode significar uma crítica social para enfatizar a noção da construção da identidade coletiva capaz de representar uma "alternativa às gangues, uma nova forma de rebelião, nos quais se reúnem em galeras que não possuem a organização própria das gangues" (ABRAMOVAY et al., 2002, p. 136). Muito provavelmente, este pensamento sintetize a captura que pretendemos apontar, na qual um modo de contestação, de rejeição de estigmas, de preconceitos, acaba sendo tornado elemento de adequação. Como se fosse necessário marcar uma diferença entre a crítica social "responsável" realizada pelos hiphoppers e a atitude violenta das gangues.

Essa mesma "esperança” de que o Hip Hop possa se constituir como um modo de construir laços sociais menos transgressores na adolescência, pode ser observada na pesquisa de Diógenes (1998, p. 123) sobre as gangues de Fortaleza: "é como se o Hip Hop tivesse sido forjado como alternativa às práticas ensejadas pelas gangues e projetasse, através da inversão dos referentes, uma mudança social".

Por fim, Almeida (1996, p. 180) sintetiza este entendimento do Hip Hop como modo de protagonizar papéis sociais menos transgressores e, em certa medida, menos ameaçadores, postulando: “envolve (sua concepção sobre Hip Hop) a afirmação de identidades sociais, não a afirmação da identidade estigmatizada, mas da identidade cidadã...”.

De certa forma, a expressão máxima de uma identidade funcional, uma identidade que conduza a uma boa sociabilidade, é a identidade cidadã. Conjugando-se com o conceito de identidade, a cidadania constitui pólo oposto àquele onde se situariam a violência, o comportamento anti-social, a delinqüência. Não se trata de uma problematização mais apurada sobre o que seja o conceito de cidadania, ou de diferentes formas de ser cidadão, como um novo modo de habitar a cidade, por exemplo. Trata-se, muito simplesmente, de concebê-la como instrumento preventivo em relação a uma suposta violência potencial dos jovens.

Dessa forma quando os jovens entram em grupos de gangues, adquirem uma identidade do "nós", tornandose prontos para expressar uma identidade de violentos, fortes, destemidos, em contraste com os fracos e medrosos (ALMEIDA, 1996, p.179). 
Ao nos depararmos com uma predominância de abordagens através das quais, tanto psicólogos [Scandiucci (2005); Matsunaga (2004); Diógenes (1998)] quanto sociólogos [Martins (2005); Abramovay et al (2002); Almeida (1996)], buscam dar ênfase ao binômio identidade/cidadania, passamos a compreender que, para além daquilo que representa cada uma das formas de expressão do Hip Hop (rap, break e grafite), é necessário ter em conta que, no Hip Hop, trata-se de jovens, na sua maioria negros e marginalizados, cuja participação na sociedade vem despertando uma preocupação crescente e que está muito ligada a um "temor de proximidade".

Se, por um lado, o teor de contestação das letras dos raps, o engajamento que provoca junto aos jovens e a tomada de atitude frente às desigualdades sociais relacionados ao Hip Hop fizeram-nos supor estratégias de resistência, por outro, tais singularidades foram sendo absorvidas pelos discursos corriqueiros da "boa sociabilidade", do bem integrar-se à sociedade, ou seja, de forma "cidadã", através do mecanismo da identificação. Por isso, em que pese certa potência de desestabilização dos discursos recorrentes sobre negritude e pobreza a qual o Hip Hop parece evidenciar, observamos também a existência de um mecanismo "homeostático" que já cria um novo modo de tornar esta potência operativa para que os modos de sociabilização e de subjetivação hegemônicos continuem como estão ${ }^{4}$. E o mecanismo que tem sido utilizado para realizar esta adequação pressupõe uma lógica identitária.

Portanto, compreendemos que não há como separar esta lógica identitária de uma racionalidade antecipatória que está ancorada no sentimento de insegurança. Não há como compreender a ascensão do conceito de identidade como ordenador do sujeito, sem levar em conta a formulação das categorias desviantes. Uma vez que é a serviço da mesma racionalidade preventiva e moralizante que vemos o conceito de identidade tornar-se operativo tanto na psicologia, integrando-se nos discursos da psicopatologia da adolescência, a fase da vida onde se dão as "identificações", quanto na sociologia, através da formulação da juventude desviante como problema social que pode ser amenizado através de "boas identidades" ou agravado através das "identidades de risco".

\begin{abstract}
Desta forma, os ritos de passagem tornam-se um espaço mais permanente de formação da identidade, espaço que não só implica elementos de uma cultura tradicional reinventada, como também um envolvimento com "culturas de risco" alternativas, que por seu turno tendem a extravasar os papéis aceitáveis em torno de classe e diferença sexual (HOLLANDS, 1997, p. 212, grifo nosso).
\end{abstract}

Neste sentido, veremos como foi se produzindo no tecido social um tensionamento que levou à construção da noção de "classes perigosas" e, ao mesmo tempo, como os modos atuais de problematização do Hip Hop não deixam de atualizar tal concepção. 


\section{URbanizaÇÃo E CONSTRUÇÃo das ClASSES PERIGOSAS}

Hall (1995, p. 27), em Cidades do Amanhã, fez uma história do urbanismo, demonstrando como o impulso para o planejamento das cidades esteve diretamente ligado ao problema da pobreza, da violência e da superpopulação:

[...] a emoção dominante não era a culpa, mas o medo. Os pobres eram geralmente retratados como grosseiros, animalescos, bêbados e imorais; a negligência e a complacência de anos e anos haviam feito com que eles se tornassem uma ameaça para a civilização.

Também Foucault (1982, p. 87) demonstrou como a urbanização emprestou novas nuances aos conflitos entre pobres e ricos:

Nasce o que chamarei de medo urbano, medo da cidade, angústia da cidade que vai se caracterizar por vários elementos: medo das oficinas e fábricas que estão se construindo, do amontoamento da população, das casas altas demais, da população numerosa demais; medo, também, das epidemias urbanas, dos cemitérios que se tornam cada vez mais numerosos e invadem pouco a pouco a cidade; medo dos esgotos, das caves sobre as quais são construídas as casas que estão sempre correndo o perigo de desmoronar.

Podemos compreender, então, que é a proximidade e a distribuição desordenada dos "pobres" pela cidade, é o seu funcionamento não convencional, sua "diferença" que vai produzir o medo e não necessariamente uma propensão violenta que existiria no pobre. A não proporcionalidade entre pobreza e violência já era evidente ainda na Inglaterra vitoriana: "O curioso é que, a despeito dos temores dos cidadãos, parece claro que a criminalidade nos últimos tempos da Inglaterra vitoriana, seguia uma contínua linha decrescente." (HALL, 1995, p. 29); ou nas palavras de Lagrange (1995 apud ZALUAR 1997, p. 30): "Na Inglaterra e na França do século XIX, quando a miséria era um dos temas literários prediletos e uma realidade visível nas ruas de suas cidades, a taxa de homicídio não passava respectivamente de 0,5 e de 1,41 ".

É, pois, um medo que vai deixando de se ligar a um objeto específico e identificável e começa a se caracterizar como uma angústia livre, não associada a nenhum perigo imediato, mas a uma violência potencial. A insegurança começa a ser estruturante de um modo de relação entre os segmentos urbanos.

Um conceito exemplar para o entendimento de como a questão da superpopulação e da pobreza é ligada à insegurança e ao medo, é o de "classes perigosas". A primeira vez que o termo "classes perigosas", segundo Guimarães (1981), apareceu na literatura foi num texto da inglesa Mary Carpentier sobre a recente massa de indivíduos que ficaram à margem do emprego de mão-de-obra na indústria inglesa na fase inicial da Revolução Industrial, na primeira metade do século XIX. Eram pessoas que já tinham passado algum tempo no sistema prisional ou 
que não possuíam um modo de garantir o sustento de sua família. A categorização destas pessoas como perigosas, porém, era devido ao fato de estarem fora do circuito capitalista da produção industrial. Portanto, a preocupação em relação a estes indivíduos é menos aquilo que, em virtude da necessidade, eles seriam capazes de fazer, do que o temor pelo que poderia representar a energia de uma mão-de-obra excedente, não empregada pela indústria do capital.

\begin{abstract}
Impor o modelo-Trabalho a toda a atividade, traduzir todo o ato em trabalho possível ou virtual, disciplinar a ação livre, ou então (o que dá no mesmo) rejeitá-las como lazer, que só existe por referência ao trabalho. Compreende-se desde logo porque o modelo-Trabalho fazia parte fundamentalmente do aparelho de Estado, no seu duplo aspecto físico e social (DELEUZE; GUATTARI, 1997, p. 200).
\end{abstract}

Neste sentido, fica evidente que a construção das categorias desviantes ou perigosas começa a se formar não apenas pelo fato de que determinadas parcelas da população sejam mais desamparadas ou tenham menor poder econômico. As classes perigosas dizem menos respeito a uma questão de pobreza em si, do que ao fato de que as mesmas não são disciplinadas pelo trabalho, "essa gente, como classe é inepta, gastadeira, amante do prazer e sempre pobre; seu ideal é trabalhar e divertir-se quando bem lhe aprouver" (BOOTH apud HALL, 1995, p. 32).

Coimbra (2001, p. 80) denuncia o modo pelo qual o capitalismo acaba naturalizando uma periculosidade da pobreza, uma vez que o termo classes perigosas refere-se ao contraste entre o modo de vida das pessoas pobres e uma "ética" capitalista, para a qual a miséria "passa a ser naturalmente compreendida como advinda dos vícios e da viciosidade inerentes aos pobres".

O termo classes perigosas é recorrente em diferentes momentos históricos, sempre que certo modo de existência escapa ao ordenamento do capital. Segundo Zaluar (1997), o conceito de classes perigosas volta a ser referido para designar, respectivamente: a vida social, política e literária na França na década de 70 , quando, após o agito de maio de 68 , havia o desejo de contestar os modos de vida hegemônicos; mas também vai ser retomado para se referir às galeras da banlieue parisiense na década de 80. Entretanto, em ambos os casos, há de se ressaltar uma descontinuidade na relação entre pobreza e violência. "As evidências históricas e estatísticas da criminalidade na França demonstram não haver diferenças entre os índices de violência de Paris e das zonas rurais na França durante o século XIX" (ZALUAR, 1997, p. 29). Da mesma forma, em relação à violência da banlieue parisiense, a autora aponta causas muito mais relacionadas com a exclusão, a segregação e o xenofobismo do que com a miséria.

Portanto, é sempre isso que vem se deslocando e metamorfoseando ao longo da história como algo à margem do circuito capitalista, denominado de classes perigosas. É na medida em que os pobres, como é demonstrado por Thompson (1998) na sua descrição da passagem da cultura patriarcal para a fase pré-industrial na Inglaterra do século XVIII, passam a ter mais direitos, 
uma vez que se apropriam de sua capacidade produtiva, que o ordenamento simbólico que os distanciava moralmente da aristocracia entra em crise. Assim, eles passam a representar uma ameaça às elites. Através do trabalho assalariado, emerge uma nova visibilidade para os pobres, criando todo um estranhamento e um conflito de seus costumes "populares" diante da moral puritana. Os pobres passam a provocar medo.

Ao chamar a atenção para o fato de que as classes perigosas dizem menos respeito a uma propensão violenta dos pobres, mas ao fato de que as mesmas não seriam disciplinadas pelo trabalho, e até mesmo, de uma determinada reação à visibilidade que a pobreza adquiriu na sociedade recém industrializada, estamos dizendo que o sentimento generalizado de insegurança que vivemos hoje também tem raízes numa concepção de desvio forjada desde uma tentativa de manter uma dominação diante de uma parcela da população que começava a comportar-se com mais autonomia.

Neste sentido, para a discussão que pretendemos trazer à tona sobre um paradigma preventivo, é importante compreendermos que um novo modo de subjetivação vai surgindo a partir do medo e se materializando de várias maneiras. Materializa-se nos termos do questionamento quanto aos modos de governar, ou seja, através do planejamento racional da cidade, produzindo a divisão e a previsão de espaços confinados para que as diferenças não se encontrem. Materializa-se, também, no impulso estatístico de gerenciar as potencialidades de uma sociedade, demarcando o lugar do desvio. E, finalmente, materializa-se na esfera do pensamento acadêmico, pelo conceito de classes perigosas.

Assim, observa-se no contexto de uma sociedade em que há uma crescente diminuição dos postos de trabalho - ou o que tem se chamado de crise das oportunidades -, uma nova retomada da noção de categorias desviantes ou de classes perigosas, só que, desta vez, encobertas por termos como "situação de risco" ou "situação de vulnerabilidade social". Na verdade, estamos experienciando, mais uma vez, a produção da juventude e da pobreza como problema social. O jovem pobre é o objeto icônico do temor das classes burguesas. Diante deste jovem, muitos atravessariam, e atravessam, a rua.

A crescente presença de "manifestações juvenis proscritas",
em geral protagonizadas por agentes sociais dos segmentos
populares, arremessou os jovens no centro de um importante
debate político intelectual, que os situa, em geral, como
um dos obstáculos à "paz" e à "ordem social". Ou seja,
a condição de "proscritos" de alguns, o preconceito, o
racismo e a sensação de incremento da violência no mundo
têm acentuado esta representação negativa do jovem
(HERSCHMANN, 2000, p. 58).

Portanto, as estratégias de atenção ao pobre e às minorias, cujo envolvimento de psicólogos e demais trabalhadores sociais é cada vez maior, sempre estiveram, em certa medida, relacionadas com o conceito de categorias desviantes. 
Atualmente, é sob o pano de fundo da convivência urbana entre os moradores das favelas e bairros pobres da cidade com os habitantes da cidade oficial, higiênica, legítima, que se vem pensando a juventude como um problema social, ou seja, na perspectiva da insegurança, do medo. Quando nos surpreendemos com o fato de que as abordagens psicológicas têm enfatizado uma potência corretiva no Hip Hop, colocada em prática através de um reforço identitário, isto nos faz questionar exatamente quais são os medos, as angústias que impulsionam tal forma de pensar. Daí é que nos deparamos com um determinado paradigma preventivo.

\section{Paradigma Preventivo}

É preciso se perguntar se, em nome dos direitos e da democracia, em um tempo de ecopolítica para o corpo são, as periferias das grandes cidades em nome da segurança, não estão se tornando novos campos de concentração, gerenciados por moralistas políticos (PASSETI, 2003, p. 14).

Uma vez que concebemos a presença do medo como um aspecto subjetivo que vem delineando o relacionamento entre segmentos urbanos, vamos chamar de paradigma preventivo ao conjunto de dispositivos que vão se constituir em torno do sentimento de insegurança urbana. É preciso levar em conta que a relação entre insegurança e violência não é causal ou natural, mas se insere no contexto da organização da sociedade em segmentos diferenciados: insegurança e violência urbana são produtos de uma tensão que vem atravessando a sociedade a partir do momento em que os indivíduos passam a estabelecer relações de pertencimento e de dependência com um poder centralizado, ou seja, quando começam a se reconhecer como elementos de um Estado, com suas vidas dependendo dele e para ele.

Considerando que a relação entre insegurança e violência urbana não é algo natural, entendemos que é apenas numa atualização do conceito de classes perigosas e de categorias desviantes que podemos pensar essa relação. Em outras palavras, o que pretendemos denunciar através do conceito de paradigma preventivo é uma "potência fascista" que, através do sentimento de insegurança, vai construindo noções de "situação de risco" ou, falando em linguagem politicamente correta, de "vulnerabilidade social" que, por sua vez, são justificadas através da problemática da violência.

Portanto, o paradigma preventivo é muito menos resultante da experiência fática da violência, cuja existência não negamos, do que de uma determinada potência microscópica, "molecular", diríamos a partir de Deleuze \& Guattari (1996), que se espalha pelo corpo social, ativando-nos a capacidade de submissão aos procedimentos necessários para nos sentirmos seguros, engendrando uma racionalidade antecipatória com tecnologias específicas. Tecnologias, estas, que não são apenas físicas (cadeados, grades e alarmes), apenas ostensivas (sorria, você está sendo filmado!), apenas funcionais (vigilantes e guarda-costas). Estas tecnologias são também intelectuais, racionais. É desta forma que este pensamento preventivo vai se imbricando nas ciências humanas e que, no caso da Psicologia, 
acaba por se traduzir no dispositivo da identidade como conceito ordenador do sujeito. E culmina com a busca em determinadas manifestações culturais juvenis como o Hip Hop, por exemplo, pela solução para o problema, uma vez que esta cultura seria apropriada para o jovem "construir uma identidade cidadã".

Cabe questionar, então, até que ponto nossas políticas para a juventude são realmente emancipatórias e até que ponto estamos tratando de engajar a energia criativa e transformadora dos jovens em lógicas cujos fins servem apenas aos interesses de uma sociedade que cada vez mais parece se estruturar sob uma índole paranóica?

\section{UNDERCLASS}

Um novo animal social irrompeu na paisagem urbana americana dos anos oitenta, que semeia pavor entre a população e suscita uma inquietude crescentenas autoridades. Sua descoberta se fez acompanhar de uma verdadeira onda midiática: não há mídia de porte que não tenha consagrado artigos, editoriais, e reportagens aos comportamentos nocivos e predadores que o caracterizam. Políticos de todas as facções fustigam, em disputa pela primazia, sua sinistra presença no coração da cidade, que representa ora o sintoma, ora a causa da delinqüência dos bairros degradados que afligem as metrópoles do país. Pesquisadores em ciências sociais e especialistas em políticas públicas foram chamados a localizar seu habitat, enumerar seus efetivos e elucidar seus hábitos a fim de elaborar meios de conter essa proliferação maligna. [...] Este animal é a underclass urbana, termo de contornos mal-definidos e de conotações sulfurosas (WACQUANT, 2001, p.107).

Wacquant (2001), em Os Condenados da Cidade, analisa a emergência de um novo modo de problematização das relações entre centro e periferias urbanas, a partir da análise do conceito de underclass. Conceito de utilização exaustiva pela mídia norte-americana dos anos 1980, e que foi posteriormente integrado sem crítica aos discursos acadêmicos. A underclass, menos que uma categoria, é o que Wacquant (2001, p. 109) chamou de "categorema: um instrumento de acusação pública". Os parâmetros para a definição do que seria a underclass estariam menos relacionados às características intrínsecas de um grupo, uma classe ou uma faixa etária, do que um amálgama de todas as pessoas "percebidas como geradoras de uma ameaça, ao mesmo tempo física, moral e fiscal, à integridade da sociedade urbana" (WACQUANT, 2001, p. 107-108).

Ao desnaturalizar o emprego do conceito de underclass, Wacquant (2001, p. 129) apontava para um "pânico moral em relação aos subúrbios" e de como existe uma percepção "behaviorista" (WACQUANT, 2001, p. 114) generalizada entre os escritos jornalísticos e universitários, no sentido de situar a problemática desde o ponto de vista dos comportamentos, anti-sociais, desviantes, violentos, etc. 
Ao problematizar uma lógica identitária no Hip Hop e apontar a ligação que esta racionalidade faz com um paradigma preventivo, estamos, assim como Wacquant (2001, p. 129), analisando o processo de "fabricação do subúrbio como problema social, merecedor da atenção de especialistas - administrativos ou científicos".

O sentimento de insegurança que reina em Quatre Mille, por exemplo, é principalmente alimentado pelo isolamento dos habitantes, pelo meio ambiente degradado do bairro e por esta pequena delinqüência que faz dos jovens os bodesexpiatórios de todos os males do bairro (WACQUANT, 2001, p. 144).

Acreditamos que é possível tomar o Hip Hop como um objeto de estudo para além da explicitação de eventuais aspectos "positivos" que este desempenharia junto aos jovens marginalizados. Uma das formas pelas quais isso é possível é começar a analisar o processo de "fabricação" desta noção de que é necessária uma identidade cultural para que os jovens pobres e negros, vistos como perigosos à ordem social, possam construir formas de sociabilidade menos violentas, apontando o modo pelo qual esta percepção se engaja num paradigma preventivo.

Assim, pretendemos elucidar a racionalidade que fez com que, em determinado momento, uma manifestação cultural juvenil como o Hip Hop, engendrada justamente no plano da crítica às diferenças sociais e ao preconceito, entre outras coisas, foi sendo modificada pelo olhar moralizante de uma sociedade disposta a antecipar-se à violência. Podemos dizer que um determinado paradigma preventivo vem dando sustentação para discursos cada vez mais segregadores em uma sociedade como a brasileira, só para nos restringirmos ao nosso próprio contexto, que vive um apartheid social no qual a distância física e moral entre as classes sociais é diretamente proporcional à concentração de renda e às desigualdades.

\section{Notas}

${ }^{1}$ Informações mais detalhadas sobre a definição e a história do Hip Hop em: PIMENTEL, Spensy. O livro vermelho do hip hop.

${ }^{2}$ Ritmo comum nas periferias de Angola.

${ }^{3}$ É importante salientar que a idéia de periferia nem sempre corresponde a um afastamento geográfico, mas a certa distância moral que determinadas zonas mais empobrecidas das cidades possuem em relação às zonas mais elitizadas. Refere-se muito mais a um processo de invisibilização de alguns espaços da cidade.

${ }^{4}$ Como na célebre frase do filme Il Gattopardo, de Luchino Visconti: "É preciso que tudo mude, para que tudo continue como era antes". 


\section{REFERÊNCIAS}

ABRAMOVAY, M. et al. Gangues, galeras, chegados e rappers: juventude, violência e cidadania nas cidades da periferia de Brasília. Rio de Janeiro: Garamond, 2002.

ALMEIDA, R. Violência urbana, inclusão social e identidade. In.: LINS, D.; BARREIRA, C. (Org.). Poder e Violência. Fortaleza: EUCF, 1996.

COIMBRA, C. M. B. Operação Rio: o mito das classes perigosas. Rio de Janeiro: Oficina do Autor/Intertexto, 2001.

DELEUZE, G.; GUATTARI, F. Micropolítica e segmentaridades. In.: Mil Platôs. São Paulo: Ed. 34, 1996. v. 3.

. Tratado de Nomadologia: a Maquina de Guerra. In. . Mil Platôs. São Paulo: Ed. 34, 1997. v. 5.

DIÓGENES, G. Cartografias da cultura e da violência: gangues, galeras e o movimento hip hop. São Paulo: Annablume, 1998.

FOUCAULT, M. O nascimento da medicina social. In.: . Microfísica do poder. 3. ed. Rio de Janeiro: Graal, 1982.

GUIMARÃES, A. P. As classes perigosas: banditismo rural e urbano. Rio de Janeiro: Graal, 1981

HALL, P. Cidades do amanhã: uma história intelectual do planejamento e do projeto urbano no século XX. São Paulo: Perspectiva, 1995.

HIP. In: Dicionário Oxford Escolar. New York: Oxford Universisty Press, 1999.

HERSCHMANN, M. O funk e o hip hop invadem a cena. Rio de Janeiro: UFRJ, 2000.

HOLLANDS, R. As Identidades Juvenis e a cidade. In.: FORTUNA, C. (Org.). Cidade, cultura e globalização. Oeiras: Celta, 1997. p. 207-230.

HOP. In: Dicionário Oxford Escolar. New York: Oxford Universisty Press, 1999.

IL GATTOPARDO. Direção: Luchino Visconti. EUA: 20th Century Fox, 1963. DVD Duplo (185 min).

MARTINS, R. Hip Hop: o estilo que ninguém segura. São Paulo: ESETEC, 2005. 
MATSUNAGA, P. S. Formações identitárias de Jovens: algumas considerações sobre os hip hoppers piracicabanos. Revista Psicologia Política, São Paulo, v. 4, n. 7, p. 67-94, jan./jun. 2004.

PASSETI, É. Anarquismos e sociedade de controle. São Paulo: Cortez, 2003.

SCANDIUCCI, G. Juventude negro-descendente e a cultura Hip Hop na periferia de São Paulo: possibilidades de desenvolvimento humano sob a ótica da psicologia analítica. 2005. Dissertação (Mestrado em Psicologia)-Instituto de Psicologia, Universidade de São Paulo, São Paulo, 2005.

PIMENTEL, S. O livro vermelho do hip hop. 1997. Monografia (Graduação em Jornalismo). Escola de Comunicação e Artes, Universidade de São Paulo, São Paulo, 1997.

THOMPSON, E. P. Costumes em comum. São Paulo: Cia das Letras, 1998.

WACQUANT, L. Os Condenados da cidade. Rio de Janeiro: Revan, 2001.

ZALUAR, A. Gangues, galeras e quadrilhas: globalização, juventude e violência. In. VIANNA, H. (Org.). Galeras cariocas: territórios de conflitos e encontros culturais. Rio de janeiro: UERJ, 1997.

Recebido em: fevereiro de 2007

Aceito em: fevereiro de 2008 